\title{
ALTERAÇÃO NA RUGOSIDADE SUPERFICIAL DOS CIMENTOS DE IONÔMERO DE VIDRO COM O USO DE DIFERENTES SISTEMAS DE POLIMENTO
}

\author{
Nicoly Guimarães Oliveira ${ }^{1}$; Alex Correa Vieira ${ }^{2}$ \\ 1. Bolsista PIBIC/CNPq, Graduanda em Odontologia, Universidade Estadual de Feira de Santana, e-mail: \\ nicolygoliveira@live.com \\ 2. Orientador, Departamento de Saúde, Universidade Estadual de Feira de Santana, e-mail: leko_vieira@ hotmail.com
}

PALAVRAS-CHAVE: Cimentos de ionômero de vidro; Polimento dentário; Ajuste oclusal

\section{INTRODUÇÃO}

O cimento de ionômero de vidro (CIV) foi desenvolvido por Wilson e Kent no final de 1960 e disponibilizado no mercado no final da década de 70 (FOOK et al., 2008; SILVA et al., 2010; RODRIGUES, 2014). Com o crescente uso e evolução deste material, no mercado odontológico atual estão disponíveis os cimentos convencionais, modificados por resina e os reforçados por metais (BACCHI et al., 2013).

Sucessivas modificações têm sido feitas com o objetivo de melhorar as propriedades físico-mecânicas desses cimentos, reduzindo assim, suas desvantagens. Entretanto, dentre as limitações do CIV é possível citar a baixa resistência à tração, desgaste e fratura, durabilidade limitada, alta solubilidade inicial, estética relativa, devido ao monocromatismo, tempo de presa prolongado e sensibilidade à umidade (FOOK et al., 2008; AZEVEDO et al.; SILVA et al, 2010; WANDERLEY et al, 2011; BACCHI et al, 2013, RODRIGUES, 2014).

Os cimentos de ionômero de vidro são indicados como base ou forramento de restaurações, selantes de cicatrículas e fissuras, em restaurações e para cimentação de peças protéticas (NAVARRO \& PASCOTTO, 1998; RODRIGUES, 2014). Com o uso cada vez mais frequente desses materiais como restaurações definitivas e estéticas, surge a necessidade de se estudar sistemas de acabamento e polimento que possam promover uma melhor lisura, reduzindo assim, a sua rugosidade superficial e diminuindo o risco de pigmentação (SASAKI et al., 2000; SCHEFFEL et al., 2012).

A rugosidade superficial dos cimentos de ionômero de vidro pode reduzir a longevidade clínica da restauração, devido à possibilidade de maior acúmulo de bactérias, levando a recidivas de lesões de cárie, irritação tecidual e problemas periodontais (SASAKI et al., 2000;). Além disso, podem gerar alteração de cor e prejuízo estético para a restauração (SCHEFFEL et al., 2012). A presença dessa rugosidade pode ser devido à fatores como, presença de bolhas durante a manipulação, quantidade de partículas inorgânicas presentes, proporção utilizada e características da matriz do cimento de ionômero de vidro (ZANCOPÉ et al., 2009; SILVA et al., 2014).

Diante disto, o objetivo do presente trabalho foi analisar a rugosidade superficial de quatro cimentos de ionômero de vidro, utilizando diferentes sistemas de polimento.

\section{MATERIAIS E MÉTODOS}

Para a realização deste estudo in vitro foram utilizados quatro cimentos de ionômero de vidro, três convencionais (Ketac Molar Easymix - 3M ESPE; Maxxion-R e ION-Z, FGM) e um modificado por resina (Vitremer, 3M ESPE). Foram confeccionados 120 corpos de provas, os quais foram divididos em 12 grupos, sendo 03 grupos com 10 espécimes para cada cimento 
ionomérico. Cada grupo recebeu um tratamento de superfície. Desta forma, alguns espécimes representaram o grupo controle, outros foram polidos com discos de óxido de alumínio SofLex Pop-On (3M ESPE) e para os demais foram utilizadas pontas para polimento Enhance (Dentsply).

Os corpos de prova foram confeccionados utilizando matrizes metálicas com orifícios circulares de $5 \mathrm{~mm}$ de diâmetro e $3 \mathrm{~mm}$ de espessura e a manipulação realizada de acordo com as recomendações do fabricante. A matriz foi acomodada sobre uma placa de vidro que continha tiras de matriz de poliéster no local referente aos orifícios da matriz, os quais foram preenchidos com o CIV, permitindo a presença de um ligeiro excesso. Sobre a superfície do orifício foram acomodadas outras tiras de poliéster e outra placa de vidro posicionada sob as tiras, com o objetivo de permitir o extravasamento do material, além de manter a superfície mais lisa. Para o Vitremer foi utilizado o fotoativador LED Valo (Ultradent Products Inc., South Jordan, UT, USA), e para os demais cimentos foi aguardado o tempo de presa inicial (3 a 4 minutos). Após a completa reação de presa, os espécimes foram removidos da matriz metálica e analisados. Os que apresentaram bolhas ou imperfeições foram excluídos da amostra.

Com o objetivo de simular o acabamento realizado em restaurações com cimento de ionômero de vidro, foram realizados desgastes com a ponta diamantada 2135 em alta rotação nos grupos 2, 5, 8 e 11, com movimentos leves e intermitentes, por 10 segundos. Posteriormente, foram polidos com os discos Sof-Lex Pop-On (3M ESPE) de diferentes granulações, na sequência fina e extra-fina, todas em baixa rotação, por 10 segundos. Os grupos 3, 6, 9 e 12 também foram submetidos ao mesmo desgaste, mas seu polimento foi realizado com as pontas de polimento Enhance (Dentsply). Em seguida, foram armazenados em saliva artificial e estufa a $37^{\circ} \mathrm{C}$.

Após 24 horas, foram submetidos à avaliação da rugosidade superficial média com o auxílio do aparelho Surftest 301 (Mytutoyo Brasil Ind. e Com. Ltda). Foram realizadas três leituras na superfície de cada espécime, uma horizontal, perpendicular e outra oblíqua a primeira. As médias dos valores obtidos foram anotadas, tabuladas e submetidas à análise estatística, através da análise de variância e teste de Tukey, com nível de significância de 5\%.

\section{RESULTADOS E DISCUSSÃO}

Tabela 01 - Rugosidade superficial média ( $\mathrm{Ra}$ ) dos grupos experimentais, em $\mu \mathrm{m}$, apresentadas como média \pm desvio padrão (dp).

\begin{tabular}{ccc}
\hline GRUPO & MÉDIA (Ra) & DESVIO PADRÃO (dp) \\
\hline G1 & 0,45 & 0,06 \\
G2 & 0,55 & 0,07 \\
G3 & 0,80 & 0,05 \\
G4 & 0,52 & 0,03 \\
G5 & 0,80 & 0,06 \\
G6 & 0,91 & 0,05 \\
G7 & 0,48 & 0,03 \\
G8 & 0,54 & 0,06 \\
G9 & 0,78 & 0,04 \\
G10 & 0,49 & 0,03 \\
G11 & 0,53 & 0,03 \\
G12 & 0,76 & 0,04 \\
\hline
\end{tabular}


O valor máximo da rugosidade superficial que não gera formação de biofilme bacteriano é de 0,2 mm na superfície da restauração (ZANCOPÉ et al., 2009; SCHEFFEL et al., 2012; COUTINHO et al., 2016). Na presente pesquisa, todos os cimentos avaliados apresentaram valores médios superiores ao valor crítico de rugosidade acima citado. Destaca-se, desta forma, a importância da realização de novas pesquisas no intuito de descobrir um sistema de polimento capaz de proporcionar superfícies com valores próximos ao ideal.

Neste trabalho, os cimentos convencionais Ketac Easymix, Maxxion-R e Ion-Z apresentaram resultados similares em relação aos grupos controles. Em seu estudo, Rodrigues (2014) analisou um CIV convencional, um modificado por resina e uma resina composta nanoparticulada. Após análise da porosidade na superfície do material, os autores constataram que o cimento convencional apresentou os piores resultados, seguido do CIV resinoso e do compósito nanoparticulado, que apresentou os melhores valores. Além de altos valores de porosidade, o autor também verificou em microscopia óptica a presença de fissuras nos espécimes ionoméricos.

A utilização de sistemas de acabamento e polimento auxilia a reduzir a rugosidade superficial e aumentar a lisura final da restauração. O acabamento apresenta o objetivo de promover um recontorno na restauração com remoção de excessos e o polimento visa reduzir a rugosidade na superfície do material (ERDEMIR et al., 2012). No presente estudo, o sistema Sof-Lex Pop-On (3M-ESPE) foi capaz de promover superfícies tão polidas quanto ao uso da matriz de poliéster nos cimentos convencionais Maxxion-R e ION-Z, observando-se a eficácia deste sistema na obtenção de uma melhor lisura superficial.

O disco Sof-Lex Pop-On (3M-ESPE), na presente pesquisa, apresentou melhores valores em comparação às borrachas abrasivas Enhance (Dentsply) para todos os cimentos convencionais testados. Porém, no cimento fotopolimerizável (Vitremer), não foi observada diferença entre estes sistemas, apresentando assim, valores semelhantes de rugosidade superficial. Sasaki et al. (2000) analisaram a utilização de sistemas de acabamento e polimento na redução da rugosidade superficial em dois cimentos de ionômero de vidro fotopolimerizáveis (Vitremer e Dyract) e um convencional (Vidrion-R). Para o acabamento foram realizados desgastes com broca multilaminada em todos os espécimes e o polimento foi feito com discos Sof-Lex ou pontas siliconadas. Os autores, após análise, chegaram à conclusão que o disco SofLex apresentou melhores resultados em comparação às pontas de silicone, o que se assemelha aos resultados encontrados no presente estudo.

\section{CONCLUSÃO:}

Apesar das diferenças em suas composições, a rugosidade superficial dos diferentes tipos de cimento (convencional e fotopolimerizável) foram semelhantes quando não polidos, com menores valores em relação aos sistemas de polimento testados e o Sof-Lex Pop-On apresentou-se como o melhor sistema de polimento para os cimentos de ionômero de vidro convencionais.

\section{REFERÊNCIAS}

AZEVEDO, M; BOAS, D; DEMARCO, F; ROMANO, A. 2010. Onde e como são brasileiros estudantes de odontologia utilizando Cimento de Ionômero de Vidro. Braz. rev oral. 24(4).

BACCHI, A.C; BACCHI, A.C.; ANZILIERO, L. 2013.O cimento de ionômero de vidro e sua utilização nas diferentes áreas odontológicas. Perspectiva 37(137):103-114. 
COUTINHO, T.C.L; BRUNO, C; BRAZ, C.P.S. 2016. Efeito do desafio erosivo in vitro na massa e rugosidade superficial de diferentes materiais restauradores. Rev Flumin Odontol. 22(45).

ERDEMIR, U; YILDIZ, E; EREN, M.M; OZSOY, A; TOPCU, F.T. 2013. Effects of polishing systems of on the surface roughness of tooth-colored materials. Journal of Dental Sciences 8(2):160-9.

FOOK, A., AZEVEDO, V.V.C., BARBOSA, W.P.F., FIDÉLES, T.B., FOOK, M.V.L. 2008. Materiais odontológicos: Cimentos de ionômero de vidro. Revista Eletrônica de Materiais e Processos 3(1):40-5.

NAVARRO, M.F.L.; PASCOTTO, R.C. 1998. Cimentos de ionômero de vidro: aplicações clínicas em Odontologia. Artes médicas.

RODRIGUES, D.S. 2014. Análise da porosidade, resistência mecânica e desgaste de cimentos de ionômero de vidro e resina composta. Universidade Fernando Pessoa- Faculdade de Ciência da Saúde, Tese.

SASAKI, M.T.; SILVA, R.C.S.P.; ARAUJO, M.A.M.; KRABBE, D.F.M.; DAMIAO, A.J. 2000. Avaliação da rugosidade superficial de cimentos de ionômero de vidro com diferentes sistemas de acabamento e polimento. Rev. Odontol. UNESP 29(1/2):81-92.

SCHEFFEL, D.L.S; RICCI, H.A; PANARIELLO, B.H.D; ZUANON, A.C.C; HEBLING, J. 2012. Desgaste e rugosidade superficial de um cimento de ionômero de vidro nanoparticulado. Rev Odontol Bras Central 21(56).

SILVA, P.I.P; BRUM, S.C; BARBOSA, C.C.N; OLIVEIRA, R.S. 2014. Avaliação da proteção ao cimento de ionômero de vidro por diferentes materiais. Uningá Review. 19(1):5-9.

SILVA, R. et al. 2010. Propriedades dos cimentos de ionômero de vidro: uma revisão sistemática. Odontologia Clínico-Científica 9(2): 125-9.

WANDERLEY, F; SILVA, G; QUEIROZ, A; FREITAS, A; ASSED, S. 2011. Utilização do ionômero de vidro em odontopediatria. Odontol. Clín.Cient. 10(1).

ZANCOPÉ, B.R; NOVAES, T.F; MENDES, F.M; IMPARATO, J.C.P; DE BENEDETTO, M.S; RAGGIO, D.P. 2009. Influência da proteção superficial na rugosidade de cimento de ionômero de vidro. ConScientiae Saúde 8(4). 